\title{
COMPLEMENTARIEDAD ENTRE LA LEY DE RIESGOS DEL TRABAJO Y EL ART. 212 DE LA LEY DE CONTRATO DE TRABAJO
}

\section{Nicolás Francisco Niewolski Cesca'}

Sumario: I. Introducción. II.- Marco normativo. III.-El trabajador impedido. IV.-El art.212 de la LCT. V.- Condición de aplicación de las normas complementarias. VI.- Elementos complementarios al art.212, LCT. VII.-Conclusiones.

Resumen: El presente informe analiza la interrelación entre la ley de contrato de trabajo y el régimen de riesgos de trabajo, en especial tomando en cuenta el proceso de recalificación y reubicación contemplado en la Res. SRT N² 216/03 y su vinculación con el despido del trabajador impedido.

Palabras clave: Trabajador. Recalificación. Reubicación. Despido. Tareas.

\section{Introducción}

El presente informe resume la ponencia efectuada en la reunión plenaria de la Sala de Derecho Laboral y Procesal Laboral de la Universidad Blas Pascal, a la que fuimos invitados por los Dres. Ricardo Francisco Seco y Edder Hernán Piazza.

Se analizará la interrelación entre las normas que rigen la desvinculación del trabajador afectado por secuelas incapacitantes parciales, de origen laboral, que imposibilitan su reinserción en el establecimiento productivo donde prestaba funciones; con las normas propias del sistema de riesgos del trabajo.

Es así que, partiendo de la conceptualización del Derecho del Trabajo como: "El conjunto sistemático de normas y principios que, de acuerdo con la idea social de justicia, regula las relaciones jurídicas que nacen a raíz del trabajo subordinado, o en relación de dependencia"2 se expondrá un análisis que contemple no sólo el artículo 212 de la Ley de Contrato de Trabajo, sino una interpretación basada en distintos institutos laborales que se interconectan. 
Como ha señalado la doctrina: "Aunque no hay relevamientos oficiales, la observación de la realidad y, en especial, de los juicios que se presentan ante los tribunales permite saber que una cantidad importante de trabajadores sufren la pérdida del empleo luego de que se les determina un porcentaje de incapacidad permanente parcial superior al $20 \%$ y a veces ante una minoración aún menor". ${ }^{3}$

Es en este contexto que se expone una forma de abordaje de la situación mediante la ampliación del plexo normativo involucrado y no solo las previsiones propias de la Ley de Contrato de Trabajo.

\section{Marco Normativo.}

A los fines enunciados precedentemente recurrimos al Convenio OIT $N^{\circ} 159$ ratificado mediante ley 23.462 (B.O., 12/6/1987), Ley de Contrato de Trabajo NN 20.744 (B.O., 27/9/1974), Ley de Riesgos del Trabajo №24.557 (B.O.,4/10/1995), decretos reglamentarios y resoluciones de la Superintendencia de Riesgos del Trabajo, en especial las N²16/03 (B.O., 28/4/03) y No 905/2015 (B.O., 4/5/2015).

\section{El trabajador impedido.}

El Convenio № 159 de la Organización Internacional del Trabajo define en su artículo primero como persona inválida a toda aquella cuyas posibilidades de conservar un empleo adecuado y de progresar en el mismo queden sustancialmente reducidas a causa de una deficiencia de carácter físico o mental. Asimismo, establece que los Estados miembros deberán considerar que la finalidad de la readaptación profesional es la de permitir que la persona inválida obtenga y conserve un empleo adecuado.

La normativa internacional tiene su reflejo en la legislación interna en las Res. SRT 216/03 y en la Ley de Contrato de Trabajo.

El art. $1^{\circ}$ de la Res. 216/03 define al trabajador impedido como aquella persona que por causa de accidente de trabajo o por una enfermedad profesional está substancialmente impedida para realizar la tarea que efectuaba previo a dicho acontecimiento, en las condiciones en las que la realizaba.

Por su parte el art.212 de la LCT regula las consecuencias normativas de una disminución definitiva en la capacidad laboral del trabajador, que pudiera generar la imposibilidad de realizar las tareas que anteriormente cumplía.

Si bien ambas definiciones se encuentran en normas distintas y de jerarquía disímil, la situación de hecho que sirve de sustrato resulta asimilable, y radica en la imposibilidad sobreviniente del dependiente para desarrollar sus tareas.

\section{a. Elementos.}

Es así que para la aplicación de la Res. SRT 216/03 se requiere la presencia de los siguientes elementos definitorios: a) acaecimiento de accidente de trabajo o enfermedad profesional, b) impedimento sustancial para realización de tareas habituales.

El art. 212 LCT por su parte requiere para su aplicación: a) disminución definitiva en la ca-

3 MAZA, Miguel Ángel, El deber de las art de recalificar a los trabajadores incapacitados como instrumento para reducir las rupturas contractuales en el marco del artículo 212 de la LCT, RC 732/2013. 
pacidad laboral del dependiente, b) imposibilidad del dependiente de realizar las tareas que venia desarrollando.

\section{b. Semejanzas.}

Ambas normas reglan las consecuencias que la imposibilidad del dependiente para desarrollar sus tareas genera. Aunque la Res. SRT 216/03 pareciera más exigente al requerir una imposibilidad para desarrollar las tareas, que califica como substancial, entiendo que dicho aditamento no modifica la ratio legis.

\section{c. Diferencias.}

La única diferencia relevante entre ambas normas finca en el antecedente lesivo que genera la imposibilidad. Así mientras el art.212 se aplica tanto a accidentes o enfermedades inculpables o las propias de la Ley de Riesgos de Trabajo ${ }^{4}$, la Res. SRT 261/03 requiere la presencia de un accidente o enfermedad profesional, la ley 20.744 es general y se aplica tanto a contingencias propias de la ley de Riesgos de Trabajo como a infortunios inculpables.

\section{d. Relación entre normas.}

En apretada síntesis dos normas pueden interrelacionarse entre sí, de cinco maneras: a) Supletoriedad, b) Subsidiariedad, c) Complementariedad, d) Suplementariedad y, e) Colisión. ${ }^{5}$

Si bien una ley resulta de jerarquía superior a una resolución administrativa nada obsta a que esta última integre la regulación de un supuesto de hecho ${ }^{6}$. Es en este sentido que la Res. SRT 216/13 complementa7 la norma contenida en el art.212 de la LCT $^{8}$, pero sólo en los supuestos de accidentes y/o enfermedades profesionales, debido al ámbito de aplicación de la citada Res. SRT que reglamenta la Ley de Riesgos de Trabajo.

\section{EL art.212 de la LCT}

El art.212 de la LCT, luego de ratificar el principio rector del Derecho del Trabajo vinculado con la vocación de permanencia de la relación laboral, establece diversos supuestos de extinción de la relación laboral que pueden presentarse como consecuencia de una incapacitación permanente del dependiente.

En el primer párrafo regula la situación promovida por la norma, es decir la reinserción del trabajador impedido en la estructura productiva sin merma salarial.

El segundo párrafo se refiere al supuesto de imposibilidad real del empleador de otorgar tareas, en cuyo caso habilita la desvinculación con el pago de una indemnización reducida.

\footnotetext{
4 ACKERMAN, Mario E., Ley de Contrato de Trabajo Comentada, Rubinzal Culzoni, Santa Fe, 2a edición,T.II,2019, p.813 expresa: “...y, a efectos de la operatividad de esta norma, siendo inculpable la incapacitación, se torna un dato irrelevante su origen, esto es, que ella haya sido provocada, total o parcialmente, por el trabajo - accidente de trabajo o enfermedad profesional- o resulte de circunstancias por completo ajenas a él...”.

5 MARTÍN VALVERDE, Antonio, Concurrencia y articulación de normas laborales, en Revista de Política Social, Madrid, jul.-set. 1978, Nº 119, ps. 5 y ss. 6 NEVES MUJICA, J., Normas y Principios del Derecho del Trabajo. THĒMIS-Revista De Derecho, 29-32-1987. Recuperado a partir de http://revistas.pucp. edu.pe/index.php/themis/article/view/11491.

7 ACKERMAN, Mario E., Relaciones entre la LRT y el régimen de los llamados accidentes y enfermedades inculpables, RC D 1941/2012, expresa: "Según anticipé, la relación de complementación entre las normas sobre accidentes y enfermedades inculpables y el régimen de reparación de daños a la salud del trabajador diseñado en la LRT, se manifiesta cuando coinciden sus ámbitos personales de aplicación y los presupuestos de hecho de ambos sistemas, pero difieren los bienes jurídicos tutelados por cada uno de ellos."

8 ACKERMAN, Mario E., Ley de Contrato de Trabajo Comentada,2a edición, Rubinzal Culzoni, Santa Fe, 2019, T.II, p. 813: "Es oportuno insistir aquí en que el mecanismo protectorio del artículo 212 de la LCT es una de las expresiones de las relaciones de complementación que se producen entre el llamado régimen de accidentes y enfermedades inculpables y el de riesgos del trabajo...."
} 
Por su parte, el tercer párrafo, sanciona la reticencia empresaria de otorgar tareas cuando ello fuera posible, y manda a indemnizar en forma plena.

Finalmente, el cuarto párrafo, a diferencia de los anteriores, se refiere al supuesto de incapacidad absoluta, donde la prestación laboral resulta imposible, y el vínculo se disuelve con indemnizaciones normales.

El presente análisis se centrará exclusivamente en las hipótesis contempladas en los párrafos primero a tercero, es decir cuando resultare una disminución definitiva y parcial en la capacidad laboral del dependiente y las consecuencias que de ella se pudiera generar en el contrato de trabajo.

\section{Condición de aplicación de las normas complementarias.}

A los fines de la aplicación articulada de las normas propias de la Ley de Contrato de Trabajo y del sistema de reparación de infortunios laborales, necesariamente la incapacitación del dependiente debe tener como origen un infortunio laboral.

La Ley de Riesgos del Trabajo, en su artículo $6^{\circ}$, define los accidentes de trabajo y enfermedades profesionales considerando accidente de trabajo a todo acontecimiento súbito y violento ocurrido por el hecho o en ocasión del trabajo, o en el trayecto entre el domicilio del trabajador y el lugar de trabajo, siempre y cuando el damnificado no hubiere interrumpido o alterado dicho trayecto por causas ajenas al trabajo.

Asimismo, se consideran enfermedades profesionales a aquéllas que se encuentran listadas, permitiendo bajo determinados supuestos la incorporación de enfermedades no listadas.

\section{Elementos complementarios al art. 212 LCT}

La complementariedad propuesta de las normas implicará que determinados conceptos adquieran un matiz propio del sistema de riesgos del trabajo, así como un procedimiento de determinación particular.

\section{a. Carácter definitivo de la incapacidad}

La complementariedad entre la Ley de Contrato de Trabajo y la Ley de Riesgos del Trabajo, decretos reglamentarios y resoluciones de la SRT resulta de suma trascendencia en este punto.

Por antonomasia puede definirse como incapacidad definitiva a aquella que no es temporaria. Sin embargo, la Ley de Riesgos de Trabajo luego de agotado el periodo de incapacidad laboral temporaria establecía un periodo entre aquella y la situación de incapacidad laboral permanente, a la que definía como incapacidad laboral permanente provisoria. Este período anómalo generó discrepancias interpretativas acerca de cuándo se configuraría la situación requerida en la Ley de Contrato de Trabajo, si al agotarse el periodo de incapacidad laboral temporaria o al agotarse la provisoriedad de la incapacidad permanente.

La sanción del decreto reglamentario 472/2014 que en su art. 2.1 del Anexo, estableció que: "Considérase que a partir de la entrada en vigencia de la Ley $N^{\circ} 26.773$, para las contingencias posteriores a la misma, la Incapacidad Laboral Permanente no tendrá situación de 
provisionalidad", puso punto final al distingo interpretativo.

Entonces, según lo normado en el art.7 de la ley 24.457 (según Ley 27.348) la situación de incapacidad laboral temporaria, finalizará por: a) Alta Médica, b) Declaración de Incapacidad Laboral Permanente, c) Transcurso de dos años desde la primera manifestación invalidante y, d) Muerte del damnificado.

Ahora, como el alta médica puede ser controvertida por el damnificado, en cuyo caso será la Comisión Médica Jurisdiccional actuante quien determinará la justeza del Alta Médica y en su caso determinará la situación de incapacidad laboral permanente; mientras no se agote el plazo impugnativo o se expida la Comisión Médica Jurisdiccional, el trabajador no se encontraría en situación de incapacidad laboral permanente.

\section{b. Carácter parcial de la incapacitación.}

El carácter parcial de la incapacitación se define en la Ley de Riesgos del Trabajo por exclusión, al definir como total aquella que iguale o supere el $66 \%$ de la Total Obrera (art. $8^{\circ}$ LRT). En el supuesto de incapacidad total, se configuraría la hipótesis del $4^{\circ}$ párrafo del art. 212 de la LCT, por lo que se excluye su análisis.

\section{c. Proceso de recalificación / reubicación.}

Las Res. SRT 216/03 establece, en consonancia con el Convenio 159 de la OIT, un procedimiento tendiente a la reubicación y eventualmente la recalificación de los trabajadores impedidos.

El procedimiento es definido como un proceso continuo y coordinado de adaptación y readaptación que comprende el suministro de medios para que los trabajadores afectados por accidentes o enfermedades profesionales puedan obtener, ejercer y conservar un empleo adecuado.

La finalidad primera del procedimiento es lograr la reubicación del trabajador siniestrado dentro de la organización a la que pertenece y recién luego de agotado el procedimiento, y frente a una real imposibilidad del empleador, recalificar al dependiente. (art. $7^{\circ}$ inc. e) ${ }^{9}$. El procedimiento tiene como partes integrantes a la Aseguradora de Riesgos del Trabajo, al empleador ya sea asegurado, autoasegurado o no asegurado, y al trabajador.

El proceso puede iniciar durante el periodo de incapacidad laboral temporaria $\left(\operatorname{art} .5^{\circ}\right)$ y consta de las siguientes etapas: a) Evaluación; b) Orientación; c) Análisis Ocupacional y adecuación del medio laboral; d) Capacitación (art. 7); e) Colocación; y durará un mínimo de tres meses, hasta un año.

Durante el periodo de Evaluación, se determinarán las capacidades y posibilidades físicas, mentales, psicosociales y profesionales que posee el afectado, realizando el profesiograma correspondiente. Se evaluará la capacidad funcional residual y las aptitudes del trabajador con el fin de establecer su posible desempeño profesional cuando se encuentre en condiciones efectivas de reiniciar su vida laboral.

9 Cam. Única del Trabajo, Córdoba, Sala VII, “Ortiz Carlos Ariel c/ Prevención ART S.A. - Ordinario - Accidente - Ley de riesgos”, 5/6/2006: “Aparece por lo tanto incumplida la Res. SRT 216/03 referida a la materia y en lo que hace a evaluación, orientación, capacitación y colocación y seguimiento (art. 7). ... Es decir, se trata de obligaciones de procurar un resultado en los planos médicos, de rehabilitación y recalificación profesional y en el marco de un sistema que debe atender integralmente a las víctimas de accidentes y enfermedades.... 
En la fase de Orientación: se efectuará un pronóstico con relación a las actividades que el damnificado pueda y quiera desarrollar, de acuerdo con las posibilidades de formación profesional, de empleo existentes o necesidades laborales en la zona donde habita o donde pueda desarrollarlas.

La etapa de Análisis Ocupacional y Adecuación del Medio Laboral comprende el relevamiento de los posibles puestos de trabajo valorando los requerimientos y oportunidades concretas de éstos y su entorno con el objeto de adecuar, en caso necesario, el medio laboral para ser ocupado por el siniestrado. Tal adecuación debe comprender infraestructura técnica que asista o supla movimientos y/o funciones que el trabajador no pueda ejecutar.

Durante el periodo de Capacitación se procurará instruir al trabajador, teniendo en cuenta las condiciones físicas y educativas lo permitan, brindando un menú de opciones orientado a que el trabajador siniestrado logre la aptitud que le permita mejorar su oportunidad de reintegrarse a la vida laboral activa, sobre la base de una tarea igual o superior a su nivel de formación previo al del accidente.

Finalmente, en la fase de Colocación: Se promoverá la reinserción del trabajador siniestrado al puesto de trabajo que ocupaba en el mismo establecimiento; de no ser posible, se evaluará a través de las habilidades del damnificado la posibilidad de reinserción laboral en otro puesto de trabajo.

La etapa final del proceso requiere de la participación de la empleadora quien, previo informe de la aseguradora acerca de las capacidades funcionales del dependiente, deberá en un plazo máximo de 15 días hábiles informar, si dará curso a la reubicación laboral y, de no ser posible dicha reubicación, indicará los motivos que la imposibilitan.

Si la empleadora no pudiera efectuar la reubicación, el damnificado será capacitado en un nuevo oficio debiendo recibir las herramientas adecuadas para poner en práctica su nueva instrucción; de verificarse que el trabajador conozca un oficio previo y conserve las capacidades funcionales para ejercerlo, se lo proveerá de las herramientas suficientes para que pueda desempeñarlo. En todo caso la A.R.T. o el Empleador Autoasegurado estará obligado a cubrir el valor de las herramientas hasta la suma equivalente a 8 veces el valor del haber mínimo garantizado que periódicamente determine la Anses.

Efectuada la reubicación el Área de Recalificación Profesional de la Aseguradora realizará, por un período de sesenta días a partir del reingreso laboral del damnificado, el seguimiento de la reubicación laboral a fin de verificar las condiciones de trabajo, remitiendo informe de esta evaluación a la S.R.T.

El informe de la empleadora acerca de las posibilidades de efectuar la reubicación del trabajador siniestrado debe tener como fundamento los requerimientos contemplados en el Art. 14 del Anexo I de la Res. 905/2015 de la SRT, es decir una evaluación y análisis de alternativas de readaptación del puesto de trabajo o cambio de tarea. Asimismo, deberá basarse en los requerimientos médicos de los puestos de trabajo - Profesiograma - (Art. 4 Anexo III Res. SRT 905/2015). 


\section{d. Dictamen de Comisión Médica.}

El dictamen de Comisión Médica Jurisdiccional es el acto administrativo jurisdiccional que: a) califica el accidente o enfermedad como de origen laboral o in itinere; b) determina el carácter de definitivo de la posible incapacidad resultante; c) establece el porcentaje de incapacidad $y, d$ ) determina los factores de ponderación entre los que se encuentran la necesidad de reubicación y recalificación del dependiente. (arts. 20/21 LRT, Res SRT 179/2015 (B.O., 26/4/2015), art. $8^{\circ}$ Ley de Riesgos del Trabajo; decreto 49/14 Anexo II (B.O., 20/1/2014).

En efecto, tanto la posibilidad de reubicación del dependiente como la necesidad de recalificación constituyen factores de ponderación dentro del baremo de determinación de porcentajes de incapacidad, influyendo en consecuencia en el valor final de la posible reparación económica.

\section{Conclusiones}

La aplicación en conjunto de las normas analizadas regla un procedimiento especial para reputar como justificado el despido de un trabajador imposibilitado según las previsiones del párrafo $2^{\circ}$ del artículo 212 de la Ley de Contrato de Trabajo.

En el sistema propio de la Ley de Contrato de Trabajo, frente a un accidente o enfermedad de carácter inculpable, se determinará la minusvalía y su carácter permanente, sin un procedimiento preestablecido, por lo que el empleador podrá optar por reubicar al dependiente o proceder a su despido. Esa decisión podrá ser revisada judicialmente, siempre teniendo en consideración que: "En el espíritu que inspira la norma del art. 212, no interesa para qué tipo de tareas haya sido contratado el trabajador, sino cuales hayan de ser aquellas que pueda realizar después de una enfermedad o accidente a efectos de hacer primar la continuidad del vinculo sobre su disolución. $Y$, sin desmedro sustancial de las facultades de organización que le reconoce la ley al empleador (art. 65 de la LCT), la norma de cuya aplicación especifica aquil se trata, lo condiciona en medida razonable...".10

Sin embargo, cuando el accidente o enfermedad incapacitante ha sido de carácter laboral, existe un proceso previo para la justificación de una eventual ruptura del contrato de trabajo.

Es así que, determinado el carácter definitivo de una incapacidad, ya sea en forma previa o con posterioridad al dictamen de la Comisión Médica Jurisdiccional, se deberá transitar por los pasos definidos en la Res. SRT 216/03.

En su caso, el empleador deberá informar a la Aseguradora la imposibilidad de reubicación y justificar su proceder en informes elaborados según las previsiones de la Res. SRT 905/15. Eventualmente se deberá aguardar el dictamen de Comisión Médica que determine la necesidad de reubicación o de recalificación del trabajador, si es que el proceso inició antes del dictamen.

El dictamen de Comisión Médica Jurisdiccional adquiere entonces un valor trascendental en tal contexto porque es el organismo administrativo el encargado de precisar no solo la fijeza del alta médica que cierra el periodo de recuperación del trabajador, sino tam- 
bién el carácter definitivo de la invalidación y fundamentalmente la necesidad o no de reubicación o recalificación del dependiente imposibilitado.

Adviértase la incongruencia que se generaría si el empleador motu propio tuviera por acreditado el carácter definitivo de una situación médica, el grado de incapacitación y la imposibilidad de reubicación, frente a un dictamen administrativo que revirtiera el Alta Médica, o que considerara que no existe incapacidad, o bien que el trabajador no amerita reubicación o recalificación ${ }^{11}$.

El tránsito por un proceso previo antes de una desvinculación no es extraño a la normativa laboral. Por ello, según lo normado en la ley 24.013 en las condiciones fijadas por la norma, el despido por causas económicas que conlleve indemnizaciones reducidas requiere en forma previa el agotamiento del proceso preventivo de crisis ${ }^{12}$. En idéntico sentido, a partir de la reforma procesal laboral en la Provincia de Córdoba, el reclamo de indemnizaciones emergentes del art. $2124^{\circ}$ párrafo de la LCT, requiere del dictamen médico administrativo (art. 83 bis inc. "d" de ley provincial 7987 modificada por la ley 10.596 (B.O., 27/12/19), cuya implementación se encuentra suspendida a la fecha.

La interpretación propuesta permitirá no sólo reducir la litigiosidad sino sobre todo asegurar los fines propios de la Ley de Riesgos del Trabajo, tales como propender a la rehabilitación, recalificación y recolocación del trabajador damnificado (art. 1 inc. "b" y "c" LRT); en respeto por: la dignidad del trabajador (art. 14 Bis de la C.N), la continuidad del contrato de trabajo ( $\operatorname{art.9^{\circ }}, \mathrm{LCT}$ ), permitiendo a la persona incapacitada conservar un trabajo adecuado e integrarse a la sociedad (art. $1^{\circ}$ Convenio OIT N¹59), otorgando un mayor grado de certeza al empleador en caso de desvinculación y una protección acabada al dependiente en cumplimiento con el principio pro homine.

\footnotetext{
11 C.Ap. Sala Laboral, Concepción del Uruguay, “Grizzia Enrique Jose vs. Yabito S.A. s/ rubros adeudados e idnemnizaciones” RC J 26350/09 que dijo: “...lo cierto es que, aun cuando pueda darse por sentado que el infortunio laboral que padeció el demandante le dejó una minusvalía incapacitante, nadie sabía en septiembre de 2015 la entidad de la misma (su porcentaje respecto de la total práctica) y, más relevante todavía, nadie sabía que carácter poseía, es decir si era definitiva o temporal. Esto no es de poca importancia dado que la demandada debió tener certeza sobre la inmutabilidad del estado mórbido que presentaba Cepeda para descartar la posibilidad de que su dolencia remitiera. Aparte de esto, y más importante para la resolución del presente caso, la ignorancia (o incerteza, para el caso da igual) de la demandada, al 11-9-2015, sobre la cuantía de la incapacidad que afectaba la salud práctica del demandante torna injustificado su accionar al dejar sin sustento la afirmación respecto a no contar con "tareas livianas". Porque si se ignora el grado de minusvalía de un trabajador y el certificado de alta nada específica ¿cómo puede determinarse que tareas puede o no hacer?. En resumen: nunca pudo saber Yabito S.A. si tenía o no tareas acordes a la incapacidad del trabajador cuando no contaba con tan esencial información...”

12 TOSELLI, Carlos Alberto - SOLÁ TORINO, Victorino, Régimen de la ley 24.013 y normas agravantes del distracto",Alveroni. Córdoba, 2009, “El complejo positivo laboral, en consecuencia, absorbe el estado de crisis empresarial, en las condiciones preapuntadas, mediante el diseño de figuras típicas que causan, primero, la suspensión del contrato de trabajo40, funcionando en esta etapa como elemento técnico justificante del daño, y segundo, el despido tarifado con una indemnización reducida, instrumentando una eximente parcial de responsabilidad, cuando ambos respondan a causas de fuerza mayor, falta o disminución de trabajo no imputable o tecnológicas y con la sustanciación, preliminar a su comunicación, de un mecanismo procedimental dirigido a la protección de la estabilidad de los trabajadores y a la defensa de la empresa ante la situación económica desfavorable mediante la resolución del estado conflictivo patrimonial o técnico del giro empresario, de estructura administrativa e instancia negocial, interrumpiendo la posibilidad de medidas de acción directa por parte de los operarios y las suspensiones o despidos de incidencia pluriindividual por parte de la empresa. Tal tipología laboral se articula en el régimen de la Ley $\mathrm{N}^{\circ} 24.013$ por intermedio del procedimiento preventivo de crisis."
} 